\title{
Estimates of the Skin Cancer Incidence in Zacatecas, México
}

\author{
J.L. Pinedo*, R. Castañeda, L.E. McBride, J.I. Dávila, F. Mireles and C. Ríos
}

Universidad Autónoma de Zacatecas (UAZ), Mexico

\begin{abstract}
In the State of Zacatecas, Mexico, 731 histopathologically confirmed cases of skin cancer were recorded: $62.1 \%$ (454) were basal cell carcinomas (BCC), 26.3\% (191) were squamous cell carcinomas (SCC) and 11.8\% (86) were melanomas (M). A significantly higher proportion was observed in women: $58.6 \%$, compared to $41.4 \%$ in men. For the ensemble of pathologies, the highest frequency corresponded to the 70-79 age group, with 156 cases (21.4\%); next highest was the 50-59 group with 95 cases (13\%). However, this type of behavior was not identical for the three pathologies. In the case of melanoma a large number of cases was encountered in the 30-39 age group. With regard to anatomical location, for BCC the most common site was the face $(55.66 \%)$, predominantly on the nose, while for SCC it was the lip. The location data indicate that solar UV radiation is a risk factor, since the head is the zone most exposed to solar radiation. Linear regression analysis showed that only the incidence of SCC is progressively increasing (at an annual rate on the order of 5\%), while BCC and M were randomly distributed in time. Skin cancer incidence, determined by studies histopathologically confirmed, was in 2007 for all three pathologies 12 cases of cancer for each 100,000 inhabitants: 7.5 cases of BCC, 3.1 of SCC, and 1.4 of M.
\end{abstract}

Keywords: Melanoma skin cancer, non-melanoma skin cancer, basal cell carcinomas, squamous cell carcinomas, UV solar radiation.

\section{INTRODUCTION}

Skin cancer is conventionally separated into two categories: Melanoma (M) and Non-melanoma skin cancer (NMSC). Melanoma, the less common skin cancer, is potentially lethal, while NMSC, the most common type of skin cancer, is highly curable.

Skin cancer is named after the type of skin cell from which it arises. Non-melanoma skin cancers are generally considered as basal cell carcinomas (BCC) and squamous cell carcinomas (SCC). BCC rarely metastasise, while SCC can spread to other parts of the body. The cancer develops in the outer layer of the skin (the epithelium). Some squamous cell carcinomas arise from lesions called solar (sun) or actinic keratoses. Since it is possible for squamous cell carcinoma to spread to other areas of the body, early treatment is important.

Much more is known about the epidemiology of melanoma than about that of NMSC [1].

World melanoma incidence rates reflect the high risk for white populations in sunny climates. Australia and New Zealand lead the world with age-standardized rates between 30 and 40 cases of melanoma per 100,000 [2].

According to the American Cancer Society, approximately 62,480 melanomas were estimated for 2008 (34,950 in men and 27,350 in women), with nearly 8,420 resulting in death $(5,400$ in men and 3,020 in women). Melanoma accounts for about three percent of skin cancer cases, but it

\footnotetext{
*Address correspondence to this author at the Ciprés 10, Frac. La Peñuela, Zacatecas, Zac., c. p. 98000 México; Tel/Fax: (492) 922 70 43; E-mail: jlpv85@hotmail.com and jlpinedo@uaz.edu.mx
}

causes more than 75 percent of skin cancer deaths [3]. Melanoma mortality more than doubled from 1975 to 2004 [4].

There are no similar data available for NMSC. Compared with other malignancies, NMSC is associated with much less morbidity and mortality. NMSC is, however, far more common than other malignancies. It has become one of the five most costly cancers to Medicare in the US, along with joint, lung and bronchus, prostate, colon and rectum, and breast cancers. These considerations give NMSC an extremely high public health significance [5].

In Australia more than $\$ 264$ million (9\% of the total costs for cancer) was spent on diagnosis and treatment in 2000-01 [6]. Australia has the highest incidence of skin cancer in the world, and NMSC is the most commonly diagnosed cancer. Basal cell carcinoma (BCC) rates in 1995 were 788 per 100,000 , an increase of $19 \%$ since 1985 . Squamous cell carcinoma (SCC) rates were 321 per 100,000 in 1995. The BCC:SCC ratio changed from $4: 1$ in 1985 to $2.5: 1$ in 1995 [7, 8]. Estimates suggest that the incidence of NMSC increased by an average of 3 to $8 \%$ per year in Australia, Europe, the US and Canada from the 1960s to the 1990s [9, 10].

Skin cancer is the most common form of cancer in the United States. According to the American Academy of Dermatology (AAD), there will be approximately one million new cases of skin cancer diagnosed in the United States in 2008. Most of these (about 800,000 to 900,000) are basal cell cancers. About 200,000 to 300,000 new SCC carcinomas are diagnosed every year in the United States [11]. In the United Kingdom reliable statistics on the incidence of NMSC are also incomplete, but it is estimated that around 100,000 people are diagnosed with it each year $[12,13]$. 


\section{Skin Cancer Records in México}

In Mexico, the recording of skin cancer data is incomplete. One reason is that skin cancer has not reached a level of priority as a public health issue, a status reflected in the fact that no national program exists for the study and prevention of skin cancer. Another reason is that since the majority of skin cancer cases do not result in mortality an indeterminate number of cases are treated without histopathological confirmation, and thus go unrecorded. Also, an unknown number of cases are never treated by a doctor.

For melanoma epidemiological studies have been few, have various focuses, and refer to different time periods. Based on the archives of the National Cancer Registry (Registro Nacional de Cáncer) and of the Malignant Neoplasms Histopathology Registry (Registro Histopatológico de Neoplasias Malignas), Parada determined a melanoma incidence in 1998 of 1.01 cases per 100,000 inhabitants [14]. According to this study, melanoma occupied the nineteenth place among the 42 types of malignant tumors.

Among joint studies of the three pathologies (BCC, SCC, and $\mathrm{M}$ ) the following stand out:

In the Hospital General de México (HGM) a study covering the period between January, 1995, and January, 2005, found 1326 cases of skin cancer: 883 BCC (67\%), 256 SCC (19\%) and $105 \mathrm{M}(8 \%)$ [15].

In the Hospital General de Zona y Medicina Familiar No. 5 del IMSS in Zacatepec, Morelos (Mexico), 55 cases of skin cancer were found between July 2, 2006, and April 3, 2007 : $36 \mathrm{BCC}(65 \%), 17 \mathrm{SCC}(31 \%)$, and $2 \mathrm{M}(3.6 \%)$ [16].

In the Clínica Hospital del ISSSTE in San Luis Rio Colorado, Sonora, 60 cases of skin cancer were recorded between 1986 and 1995: $46 \mathrm{BCC}(76 \%), 9 \mathrm{SCC}(15 \%)$ and $4 \mathrm{M}$ (6.6\%) [17].

In the State of Zacatecas prior to the present work no epidemiological study in relation to skin cancer had been completed.

Zacatecas is one of the 32 states composing the República Mexicana (Mexico). With a land area of 75,416 square kilometers, it is located in the northern central part of Mexico, spanning the Tropic of Cancer. Elevation varies between 1800 and 2250 meters above sea level. The minimum length of daylight in winter is 10 hours 47 minutes, and the maximum in summer is 12 hours 8 minutes.

The general objective of the present work was to determine the incidence of skin cancer in the State of Zacatecas during the period from 1998 to 2007. It was assumed that the incidence of skin cancer must be appreciable and that it must be increasing with time, as a consequence of the state's geographic location, its high levels of solar radiation, the significant diminution of the total column of stratospheric ozone [18], and the changes in habits (notably the increase in exposure to the sun and the disuse of the hat).

The work provides the first statistics on skin cancer incidence in Zacatecas, and confirms the hypothesis in the case of SCC.

\section{MATERIALS AND METHODS}

The study population consists of patients from the state of Zacatecas with a histopathologically confirmed diagnosis of malignant skin tumor. The sources of data were the archives of neoplasms maintained by the health institutions of the state: the Instituto Mexicano de Seguro Social (IMSS), the Instituto de Seguridad y Servicios Sociales de los Trabajadores de Estado (ISSSTE), and the Secretaría de Salud de Zacatecas (SSZ).

In 2007 the IMSS had 345,875 affiliated members and the ISSSTE 91,810 . The SSZ does not have a proper figure for the number of its affiliates. Beginning in 2005 the Seguro Popular was instituted in Mexico and by 2007 the SSZ already listed 140,890 affiliated members. Nevertheless, the SSZ, through the Hospital General and the Centros de Salud, renders services to a much larger sector of the population than its affiliated members, but there exists no official, precise number to describe it. This study covers both the population with Social Security rights $(578,575)$ and the patients who visit the Centros de Salud and the Hospital General of the SSZ.

From the pathology services of the three institutions (IMSS, ISSSTE and SSZ) 113,823 biopsy forms collected between 1998 and 2007 were reviewed. Those corresponding to skin cancers were selected; from them the patients' data were taken: age, sex, examination date, physician, probable diagnosis, confirmed diagnosis of the type of skin cancer, and location of neoplasm.

There were 731 skin cancer cases found. The three types of skin cancer (BCC, SCC and M) were classified by sex, age and anatomical location of the neoplasm. The possible increase rates of the three pathologies were studied by means of linear regression. Finally, the annual skin cancer incidence was evaluated, by pathology.

\section{RESULTS}

Between 1998 and 2007 there were 113,823 biopsies carried out in the health institutions of the state of Zacatecas (Fig. 1). The IMSS, the institution with the most members, was responsible for 60,628 biopsies. The SSZ, though third in number of affiliates, was second in the number of biopsies with 33,307 , demonstrating the fact that it covers a much larger population than its number of affiliates indicates. The ISSSTE performed 19,888 biopsies.

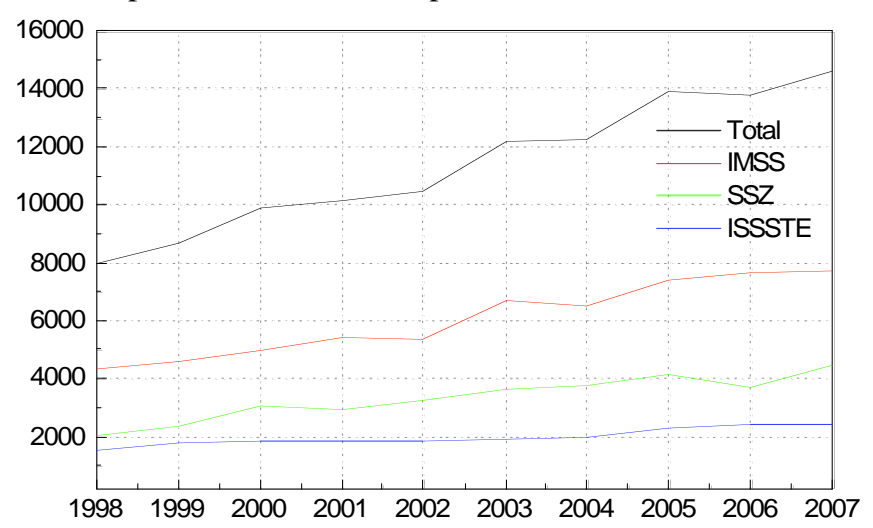

Fig. (1). Biopsies carried out in Zacatecas (1998-2007), by institution. 
From the total number of biopsies carried out in this period 731 cases of skin cancer were found in the three institutions $(0.64 \%$ of the total number of biopsies). The greatest number of skin cancer cases was detected in the IMSS (Fig. 2), although in a smaller ratio to the number of biopsies performed $(0.59 \%$ of the samples). The ratio for the ISSSTE was $0.96 \%$ and for the SSZ $0.54 \%$. Of the 731 skin cancer cases at the three institutions, $454(62.1 \%)$ were BCC, 191 were SCC, and 86 cases $(11.8 \%)$ were M (Fig. 3 ).

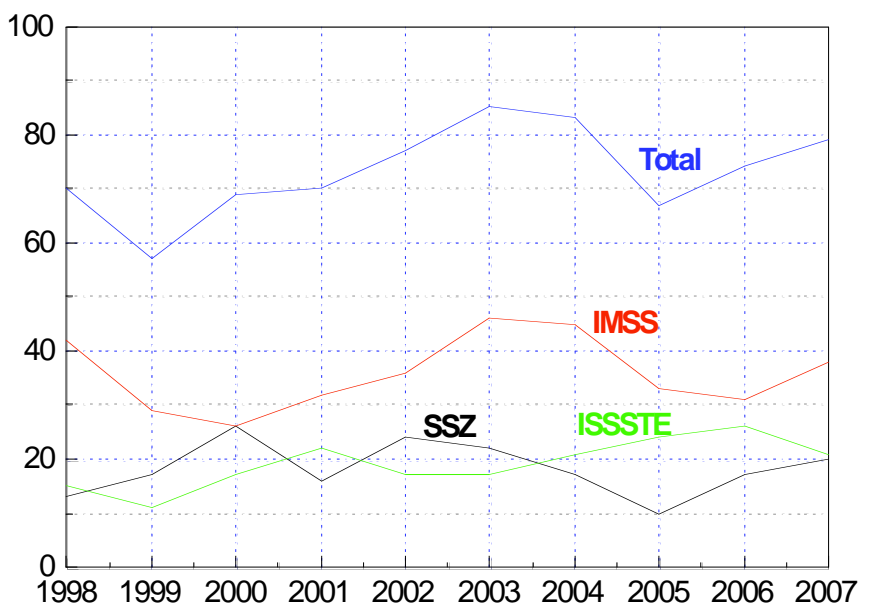

Fig. (2). Skin cancer cases recorded in Zacatecas (1998-2007), by institution.

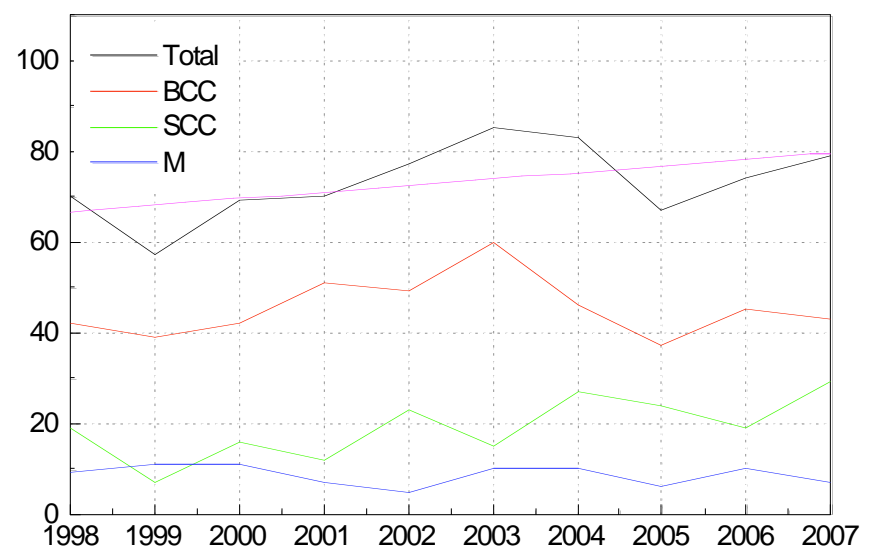

Fig. (3). Skin cancer cases recorded in Zacatecas (1998-2007), by pathology.

A gradual increase can be observed in the total number of skin cancer cases. Linear approximation (magenta line Fig. 3) shows the tendency to be equivalent to an increment of 1.436 cases per year, or $1.8 \%$ per year in 2007 . However, the correlation coefficient was very low $(r=0.523)$, so that one cannot conclude that a growth tendency exists for the ensemble of typologies.

Linear regression analysis of individual cancer types showed that only the case of SCC exhibits a progressive increase.

BCC exhibits random behavior (Fig. 4), with a peak in 2003 (10 more cases than in 2002) and another smaller one in 2006. The mean was on the order of 45 new cases per year. The number of cases in women is permanently higher than in men, the F:M ratio being 1.6:1. The 2003 and 2006 peaks are due to cases in women. So in effect linear regression analysis reveals no growth tendency.

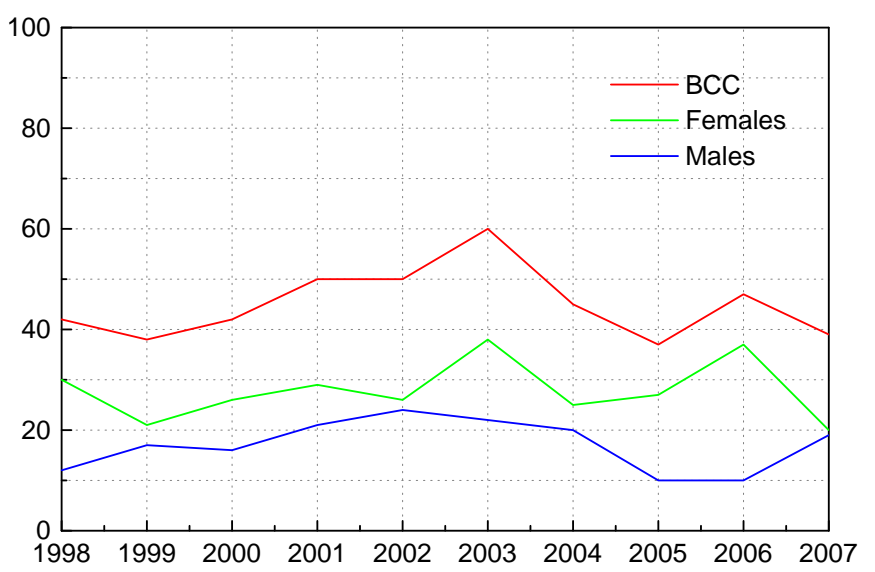

Fig. (4). Cases of BCC in the state of Zacatecas (1998-2007).

SCC's behavior is clearly progressive (Fig. 5). During the study period 90 cases in men (M) and 97 in women (F) were presented. The F:M ratio was on the order of 1.1:1. Linear approximation (Fig. 5, red line) with a correlation coefficient of $r=0.672$ shows a mean increment of 1.52 cases per year, or $5 \%$ per year in 2007.

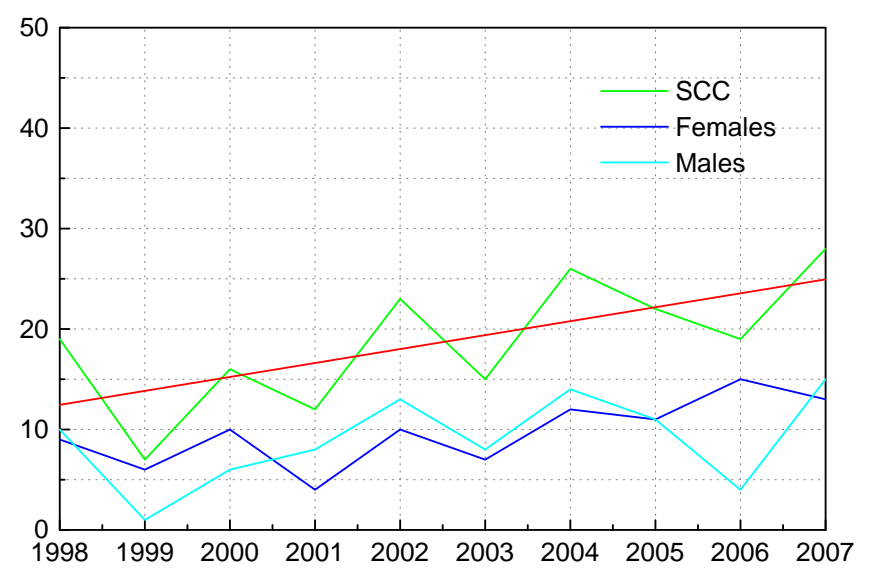

Fig. (5). Cases of SCC in the state of Zacatecas (1998-2007).

The number of melanoma cases exhibited a random behavior (Fig. 6). During the study period a mean of 8.6 new cases per year was observed. The F:M ratio was on the order of $1.3: 1$.

Fig. (7) presents the distribution of skin cancer by sex and histopathological diagnosis. A markedly higher proportion is observed in women $(\mathrm{F})$. During the study period (1998-2007) the observed ratios of cancer cases between women's and men's (F:M) by pathology were: for BCC, 1.6:1; for SCC, 1.1:1; and for M, 1.3:1.

Fig. (8) presents the skin cancer case distribution by age. The greatest frequency occurs in persons between 70 and 79 years of age. 54\% of cases appear in persons of between 60 and 90 . 


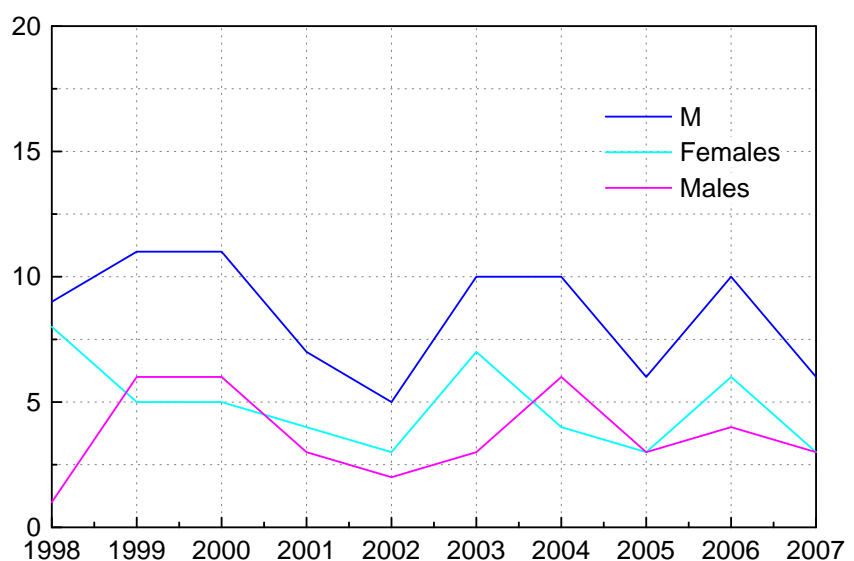

Fig. (6). Melanoma cases in the state of Zacatecas (1998-2007).

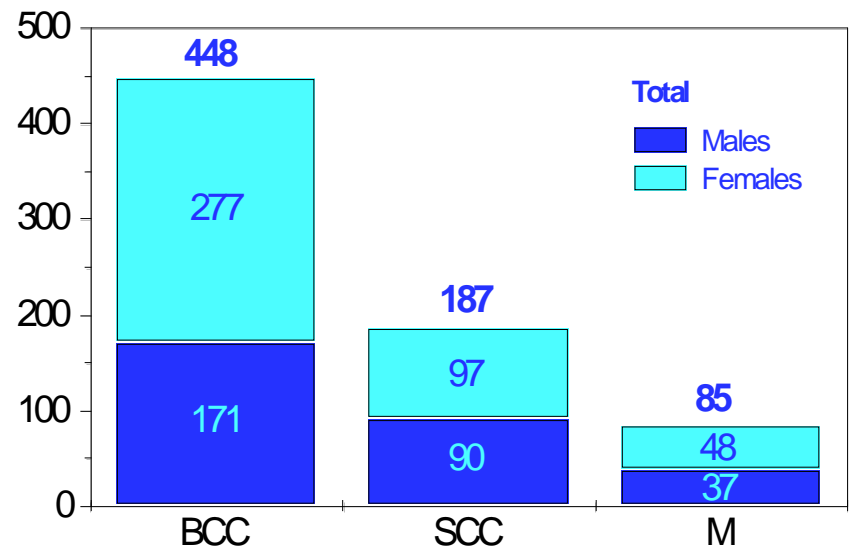

Fig. (7). Skin cancer distribution in Zacatecas (1998-2007), by type and sex.

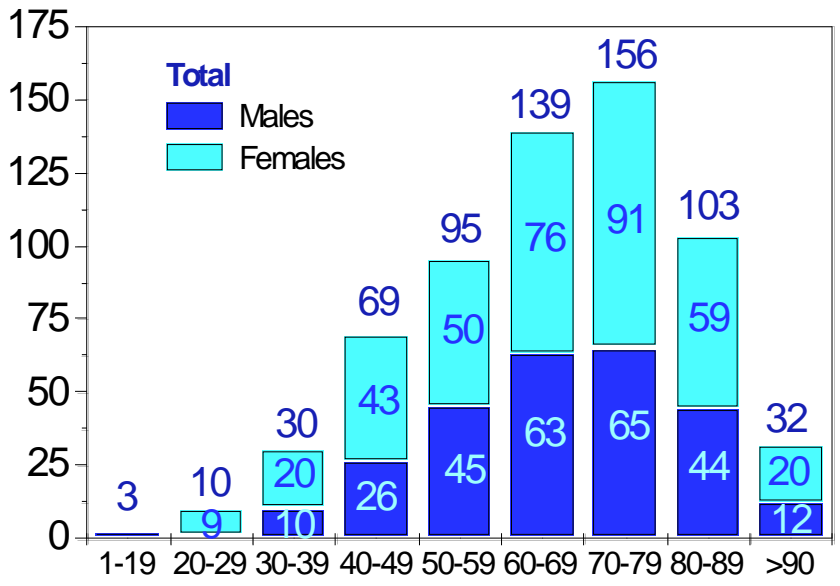

Fig. (8). Skin cancer frequency distribution (1998-2007) by age group.

It should be noted that, because of omissions in the records, in 90 cases, 39 men and 51 women, the patients' ages were not specified.

\section{Anatomical Distribution of Neoplasms}

It should be noted that only in 293 cases do the clinical skin cancer archives specify the site of the neoplasm. Although the location is unknown in a majority of the cases, it may be assumed that the archives that do specify the site constitute a rep- resentative sample of the whole, since the omissions were made for lack of foresight and not for deliberate exclusion.

Fig. (9) shows the anatomical location of neoplasms of the three different skin cancer types during the period of study. In $82.2 \%$ (241) of the cases lesions are located on the head, and in $3.7 \%$ (11) on the trunk. This fact is evidence that the risk factor is solar UV radiation, since the head is just that zone most exposed to solar radiation.

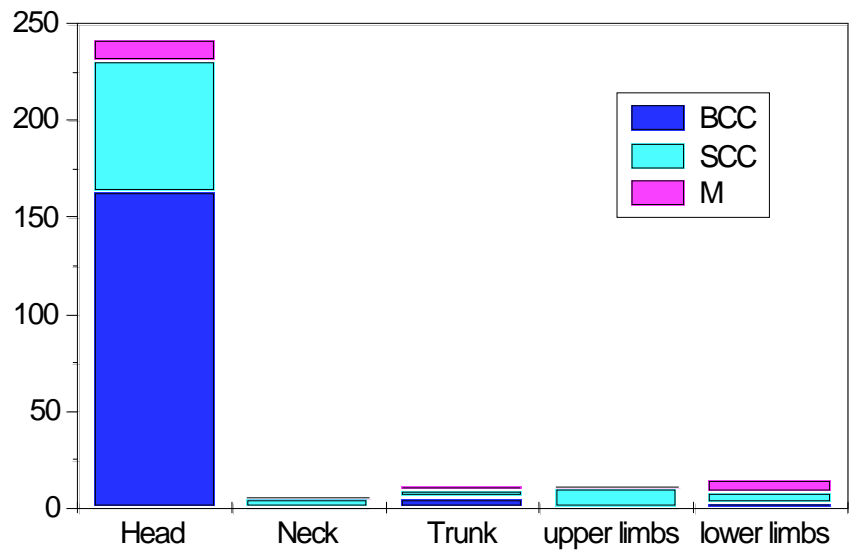

Fig. (9). Topographical location of the three different types of skin cancer, during the study period.

Fig. (10) shows the distribution of cases involving the head. The nose, eyelids and ears are the organs most affected by BCC, while the lips seem to be those most subject to SCC. The cases involving the nape of the neck are undoubtedly due to failure to wear a hat.

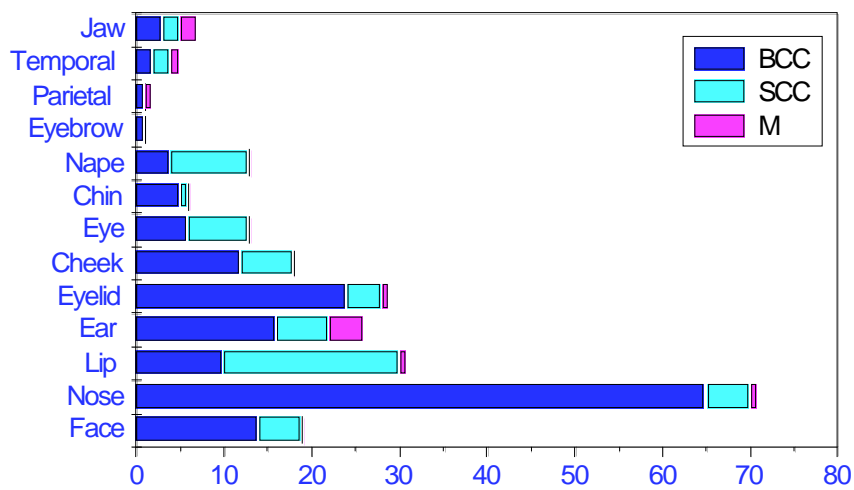

Fig. (10). Anatomical location of skin cancer pathologies on the head.

\section{Determination of Skin Cancer Incidence in the State of Zacatecas (1998-2007)}

Incidence is defined as the number of cases per hundred thousand inhabitants. It is a parameter permitting comparison among diverse populations. However, its determination requires knowing or estimating the study population. In this study, the population is constituted by the totality of rightsholders of the public health institutions IMSS, ISSSTE and SSZ. In 2007 the number of affiliates was 345,875 for the IMSS and 91,810 for ISSSTE. However, there are no precise official data regarding the total coverage of the SSZ.

The population receiving health services from the SSZ was estimated by assuming that the ratio between the number of rights-holders and the number of histopathological 
studies is approximately the same for the SSZ as the ratio between affiliates and histopathological studies for the IMSS. In the case of the IMSS this ratio is 5.7. Since the number of biopsies by the SSZ was 33,307, application of the factor (5.7) leads to the conclusion that the total population receiving services from the SSZ must be on the order of 189,850 . Thus the total population for the study was assumed to be 627,535 persons.

Skin cancer incidence was calculated by dividing the number of cases of skin cancer -histopathologically confirmed- by the total population for the study. In 2007, for all three pathologies the result was 12 cancer cases per 100,000 inhabitants. By pathology, the incidences per 100,000 inhabitants were found to be 7.5 for $\mathrm{BCC}, 3.1$ for $\mathrm{SCC}$, and 1.4 for $\mathrm{M}$.

\section{DISCUSSION}

This first study of skin cancer incidence in Zacatecas, México, (a state on the Tropic of Cancer, at altitudes of about $2000 \mathrm{~m}$ above sea level, with a predominantly darkskinned population) reveals appreciably higher rates than studies covering Mexico as a whole, but much lower incidence than that in many other countries. No previous epidemiological study in Mexico analyzed incidence of the three skin cancer pathologies, and this work is the first to provide skin cancer incidence statistics for the state of Zacatecas.

Relative frequencies of SCC and M in Zacatecas (26.3\% SCC, and $11.8 \% \mathrm{M}$ ) were greater than that found for patients from all states of the republic in the Hospital General de Mexico study, the most complete ever carried out in Mexico (19\% SCC and 8\% M). Melanoma incidence in Zacatecas (1.4 cases per 100,000 inhabitants) was appreciably higher than that reported by Parada, in the only study reporting melanoma incidence in Mexico (1.01 cases per 100,000 population) [14]. In $82.2 \%$ of skin cancer cases the anatomical location was the head - predominantly on the nose for BCC and on the lip for SCC-. All this findings are assumed to be a consequence of the state's geographical location, particularly its altitude and its high levels of UV solar radiation.

The observed case ratio between females and males (F:M) was 1.42:1 for the ensemble of pathologies; it was 1.6:1 for BCC, 1.1:1 for SCC, and 1.3:1 for M. It should be noted an inverse F:M ratio, in comparison to predominantly whiteskinned populations. The significantly higher proportion observed in women, apparently characterize the Mexican population. Among the few studies in Mexico: Gutierrez mentioned a ratio F:M, in the order of 2:1 for BCC [19]; and Parada mentioned a ratio $\mathrm{F}: \mathrm{M}$ for $\mathrm{M}$ in the order of 1.2:1 [14].

The low skin cancer incidence values may be interpreted as a consequence of the predominance of dark skin in the population of the state of Zacatecas. The limitation of the study in this regard lies in the fact that in no instance do the histopathological records specify the patient's skin type.
More complete statistics on melanoma and NMSC in Mexico are needed, particularly data regarding patient skin color, residence elevation (hence exposure to UV solar radiation) and cancer cases not treated by a State agency or not verified by biopsy. A standard form for data registry should be developed to better analyze the causes and prevalence of skin cancer.

\section{REFERENCES}

[1] Boyle P, Doré JF, Autier P, Ringborg U. Cancer of the skin: a forgotten problem in Europe. Ann Oncol 2004; 15: 5-6.

[2] Parkin DM, Bray F, Ferlay J, Pisani P. Global cancer statistics, 2000. CA Cancer J Clin 2005; 55: 74-108.

[3] Ries LAG, Melbert D, Krapcho M, et al. SEER Cancer Statistics Review, 1975-2005, National Cancer Institute. Bethesda, MD 2008; [cited 2009 March 15]. Available from: http://seer.cancer. gov/statfacts/html/melan.html

[4] SEER Cancer Statistics Review, 1975-2004 (NCI) 2008; [cited 2009 March 15]. Available from: http://seer.cancer.gov/csr/1975_ 2004/results_merged/sect_16_melanoma.pdf

[5] Housman TS, Feldman SR, Williford PM, et al. Skin cancer is among the most costly of all cancers to treat for the Medicare population. J Am Acad Dermatol 2003; 48: 425-9.

[6] AIHW (Australian Institute of Health and Welfare). Health system expenditures on cancer and other neoplasms in Australia, 2000-01. Health and Welfare Expenditure Series 2005; 22.

[7] Staples MP, Elwood M, Burton RC, Williams JL, Marks R, Giles GG. Non-melanoma skin cancer in Australia: the 2002 national survey and trends since 1985. Med J Australia 2006; 184: 6-10.

[8] Staples MP, Marks R, Giles G. Trends in the incidence of nonmelanocytic skin cancer (NMSC) treated in Australia 1985-1995: are primary prevention programs starting to have an effect? Int $\mathbf{J}$ Cancer 1998; 78: 144-8.

[9] Office for National Statistics: Registration of cancer diagnosed in 2006, England. Series MB1 No 37; [Cited 2009 March 15]. Available from: http://www.statistics.gov.uk/downloads/theme_ health/MB137/MB1_37_2006.pdf

[10] Ferlay J, Autier P, Boniol M, Heanue M, Colombet M, Boyle P. Estimates of the cancer incidence and mortality in Europe in 2006 Ann Oncol 2007; 18: 581-92.

[11] ACS (American Cancer Society). Cancer Facts \& Figures, 2008; [cited 2009 March 15]. Available from: http://www.cancer. org/downloads/STT/2008CAFFfinalsecured.pdf

[12] Holme SA, Malinovszky K, Roberts DL. Changing trends in nonmelanoma skin cancer in South Wales, 1988-98. Br J Dermatol 2000; 143: 1224-9.

[13] Toms JR, Ed. Cancer Stats Monograph. London: Cancer Research UK 2004.

[14] Parada J, Pineda B, León G. Melanoma Maligno Cutáneo. Perfil epidemiológico en México, Revista Médica del Hospital General de México 2000; 40: 17-22.

[15] Reyes G, Romero AL, Alcántara P, Mata MP, Parraguirre S, Vega E. Caracterización epidemiológica y concordancia clínicopatológica del cáncer de piel en el Hospital "Dr. Manuel Gea González”. Dermatología Cosmética, Médica y Quirúrgica 2007; 5: 807 .

[16] López ZC. Incidencia de Carcinoma Basocelular y Epidermoide. Dermatología Rev Mex 2007; 51: 149-53.

[17] Correa MA. Cáncer de Piel en la Clínica Hospital ISSSTE, San Luís Río Colorado, Sonora (1986-1995). Memorias: XVII Congreso Mexicano de Dermatología 1996; 327-31.

[18] Presbítero A. Caracterización del espesor de la capa de ozono en Zacatecas del 2003 al 2005. Tesis: UACQ-UAZ 2006

[19] Gutierrez RM. Cancer de Piel. Rev Fac Med UNAM 2003; 46 : 146 